\title{
A Rare Cause Underlying Dyspnea: Spontaneous Pneumomediastinum
}

\author{
Muhammet Gokhan Turtay ${ }^{\mathrm{a}, \mathrm{b}}$, Esra Karaman ${ }^{\mathrm{a}}$, Hakan Oguzturk ${ }^{\mathrm{a}}$, Irfan Bayhan ${ }^{\mathrm{a}}$
}

\begin{abstract}
In this case report, by drawing attention to the diagnosis of spontaneous pneumomediastinum (SPM), a review of literature was aimed. A 25-year-old male patient was admitted to the emergency service with the complaint of shortness of breath which continued for 20 days. Vital signs were normal in his physical examination but bilateral bronchospasm was found in his lung examination. Image of pneumomediastinum in chest radiography was suspicious. Pneumomediastinum and subcutaneous emphysema were detected at thorax tomography. SPM should be considered in the differential diagnosis of patients who are admitted with the complaint of dyspnea.
\end{abstract}

Keywords: Spontaneous pneumomediastinum; Dyspnea; Thorax tomography

\section{Introduction}

One of the most important causes of admittance to hospitals, especially to emergency services, is dyspnea. Mostly, lung and heart diseases are thought for patients who are admitted with the complaint of dyspnea. However, spontaneous pneumomediastinum (SPM) which is a rare cause for patients admitted with the complaint of dyspnea should also be thought. In this case report, by drawing attention to the diagnosis of SPM, a review of literature was aimed.

\footnotetext{
Manuscript accepted for publication February 11, 2014

${ }^{a}$ Department of Emergency Medicine, School of Medicine, Inonu University, Malatya, Turkey

${ }^{\mathrm{b}}$ Corresponding author: Muhammet Gokhan Turtay, Department of Emergency Medicine, School of Medicine, Inonu University, 44280 Malatya, Turkey. Email: mgturtay@gmail.com
}

doi: http://dx.doi.org/10.14740/jmc1693w

\section{Case Report}

A 25-year-old male patient was admitted to the emergency service with the complaint of shortness of breath which continued for 20 days. He reported that his complaints increased especially for a few days and that he became worried very much. There was no illness or trauma which was known in his history. He was not a smoker. Vital signs were normal in his physical examination but bilateral bronchospasm was found in his lung examination, so oxygen and salbutamol therapy was started for the patient. The blood tests required for the patient were normal, except that the white blood cell was $19,100 / \mu \mathrm{L}$. The electrocardiogram did not show any abnormalities. However, the image of pneumomediastinum (PM) in chest radiography (Fig. 1) was suspicious, so thorax tomography was taken for the confirmation of the diagnosis and in terms of differential diagnosis (Fig. 2). PM and subcutaneous emphysema (SCE) were detected at thorax tomography. Then the patient was admitted to the thoracic surgery clinic. As there were no complications, the patient who was followed for a day with oxygen therapy was taken out from follow-up.

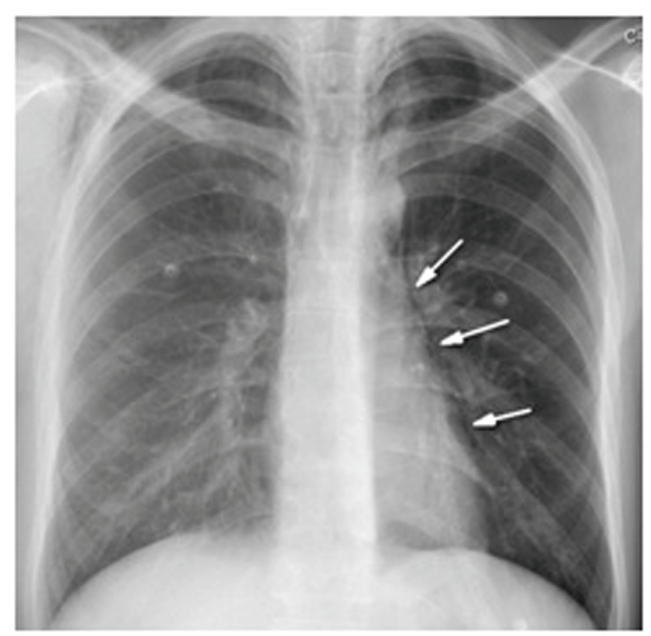

Figure 1. The image of pneumomediastinum in chest radiography. 


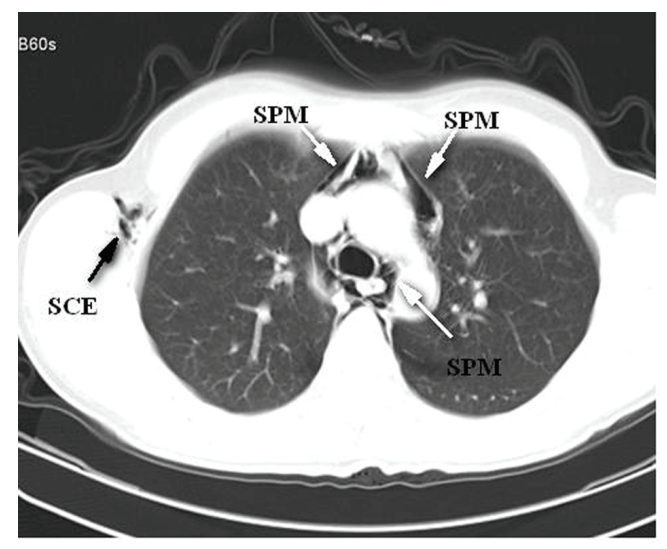

Figure 2. The image of spontaneous pneumomediastinum (SPM) and subcutaneous emphysema (SCE) in thorax tomography.

\section{Discussion}

SPM is uncommon and is reported in one in 30,000 emergency applications in a year [1]. Most often it affects young males [2]. Our patient who is 25 years old male was compatible with literature.

Main causes of PM are trauma, infections, esophageal rupture and iatrogenic factors [2, 3]. Pathophysiology under SPM is reported as increased intrathoracic pressure developed in conditions such as coughing, vomiting, birth and Valsalva maneuver [4]. Moreover, asthma, smoking and physical effort are factors related to patient's history [5]. However, in our case, no reason which can be the cause of this condition was detected.

In the symptoms and signs of SPM, chest pain, dyspnea, SCE, voice changes, dysphagia, overly anxiety, sore throat, swelling on face and neck and Hamman's sign can be detected $[4,6]$. Our patient had dyspnea and was overly anxious.

Thirty percent to $50 \%$ of SPM is detected with chest $\mathrm{X}$-ray [6]. When chest X-ray is not sufficient to diagnose, thorax tomography has high-level sensibility for diagnosing
PM [2]. For our patient, PM diagnosis came with thorax tomography after suspecting from the chest X-ray asked.

Mortality of PM is very high when accompanied with esophageal rupture [5]. Complications that are associated with PM include single-sided, double-sided or tension pneumothorax and tension PM, but they rarely appear [4]. They generally have a benign course [5]. Its treatment is resting, oxygen therapy and analgesia [6].

As a result, the SPM should be considered in the differential diagnosis of patients who are admitted with the complaint of dyspnea. In terms of the complications of the disease and/or serious conditions associated with it, early diagnosis and follow-up are so important.

\section{References}

1. Newcomb AE, Clarke CP. Spontaneous pneumomediastinum: a benign curiosity or a significant problem? Chest. 2005;128(5):3298-3302.

2. Tezel C, Varer P, Baysungur V, Okur E, Halezeroglu S. Spontaneous pneumomediastinum: report of two cases. Ulus Travma Acil Cerrahi Derg. 2011;17(4):368-370.

3. Ozturk E, Yucel A, Turtay MG, Aydogan MS, Tekdemir D, Ersoy MO. Pneumomediastinum, Pneumoperitoneum, Pneumothorax and Cervical Subcutaneous Emphysema Following Diagnostic Colonoscopy: A Case Report. Journal of Inonu University Medical Faculty. 2009;16(3):185-187.

4. Breakey RW, Walker G, Oldfield W. Spontaneous pneumomediastinum presenting as rhinolalia and chest pain. Ann R Coll Surg Engl. 2012;94(8):e243-245.

5. Sirotkin L, Ladde JG. A case of spontaneous pneumomediastinum and epidural pneumatosis in a young woman in the Emergency Department. J Emerg Med. 2013;44(5):e353-355.

6. Singla M, Potocko J, Sanstead J, Pepper P. Ooh-rah! An unusual cause of spontaneous pneumomediastinum. Mil Med. 2012;177(11):1396-1398. 